\title{
Pengaruh Modal Usaha dan Teknologi Terhadap Produktivitas di Industri Pengolahan Bahan Baku Pupuk (Studi di Industri UD. Laut Karya, Desa Sidohasri, Kecamatan Kenduruan, Kabupaten Tuban, Jawa Timur)
}

\author{
Juliani Pudjowati, Susi Tri Wahyuni, *Maulida Nur Fauza \\ Program Studi Ekonomi Pembangunan Fakultas Ekonomi dan Bisnis \\ Universitas Bhayangkara Surabaya, Indonesia
}

DOI: $10.46821 /$ ekobis.v1i2.26

\begin{abstract}
ABSTRAK
Penelitian ini bertujuan untuk menguji dan menganalisa pengaruh Modal Usaha dan Teknologi terhadap Produktivitas industri bahan baku pupuk di UD. Laut Karya. Penyebaran data dilakukan melalui penyebaran kuesioner dan dilaksanakan pada 33 pekerja pada UD. Laut Karya. Analisis ini menggunakan Analisis Linier Berganda. Teknik sampling yang dipakai adalah teknik sampling jenuh dan teknik pengujian data yang digunakan dalam penelitian ini meliputi uji validitas, uji reliabilitas, dan analisis regresi linier berganda. Hasil analisis linier berganda memperoleh persamaan $\mathrm{Y}=0,951+0,462 \mathrm{X} 1+0,321 \mathrm{X} 2$. Dengan perhitungan. Nilai Signifikansi F sebesar 0,000 artinya variabel Modal Usaha dan Teknologi berpengaruh simultan terhadap Produktivitas. Nilai signifikansi $t$ Modal Usaha sebesar 0,001 lebih besar kecil dari 0,05 artinya Modal Usaha secara parsial berpengaruh terhadap Produktivitas, dan nilai signifikansi $t$ Teknologi lebih kecil dari 0,05 artinya Teknologi secara parsial berpengaruh terhadap Produktivitas.
\end{abstract}

Kata kunci : Modal Usaha, Teknologi, Produktivitas, Industri Bahan Baku Pupuk

\begin{abstract}
The research aims to examine and analyze the influence of business capital and technology on productivity of the fertilizer industry In UD. Laut Karya. Data collected through distribution of questionnaires and it of conducted on 33 labors in UD. Laut Karya. Analysis data in this research using the help of multiple liniear regression analysis. The sampling technique used is census methods and data test technique is used within the research include validity test, reliability test, and multiple linear regression analysis. Result of multiple linear regression analysis to obtain the equation $\mathrm{Y}=0,951+0,462 \mathrm{X} 1+0,321 \mathrm{X} 2$. Calculation by $\mathrm{F}$ signification value 0,000 it means business capital and technology on productivity. $\mathrm{T}$ signification business capital is 0,001 smaller than 0,05 it's means business capitel in partially has an effect on the productivity. Meanwhile $t$ signification value of technology smaller than 0,05 it's means technology in partially has influence on productivity.
\end{abstract}

Keywords : Business Capital, Technology, Productivity, The Fertilizer Industry 


\section{PENDAHULUAN}

Sektor industri diyakini sebagai sektor yang dapat memimpin sektor-sektor lain dalam perekonomian demi menuju kemajuan. Dalam buku Machmud (2016:198) sektor industri merupakan sektor yang harus dikembangkan karena produk-produk industrial selalu memiliki "dasar tukar" (term of trade) yang lebih tinggi atau lebih menguntungkan, serta memiliki nilai tambah yang lebih besar dibanding produk sektor lain. Selain itu, sektor industri juga memiliki variasi produk yang sangat beragam dan mampu memberikan manfat marjinal yang lebih tinggi kepada kepada pemakainya. Alasan lain adalah margin keuntungan sektor industri lebih menarik dibanding sektor lainnya, dan proses produksi serta penanganan produknya lebih bisa dikendalikan oleh manusia.Dalam mengoperasikan suatu industri diperlukan baberapa faktor seperti modal usaha dan teknologi agar suatu industri dapat meningkatkan produktivitasnya. Seperti permasalahan yang terjadi di UD. Laut Karya pada modal usaha dan teknologinya. Permasalahan pada modal usaha karena modal usaha yang digunakan pada industri tersebut hanya berasal dari modal pribadi sang pemilik. Sedangkan pada teknologi, kurangnya teknologi seperti mesin pengering untuk mengeringkan pupuk fosfat, inilah yang menjadi kendala pada industri UD.Laut Karya.

\section{TINJAUAN PUSTAKA}

\section{Modal Usaha}

Modal usaha menurut Agustina (2015:57) diartikan sebagai dana yang dipergunakan untuk menjalankan usaha agar dapat berlangsung. Dalam berwirausaha, modal dapat diartikan dari berbagai segi, yaitu modal untuk pertama kali membuka usaha, modal untuk melakukan perluasan usaha dan modal untuk menjalankan usaha sehari-hari.

\section{Teknologi}

Menurut Arsyad (2016:259), ada berbagai macam definisi mengenai teknologi antara lain, teknologi dipandang sebagai sebuah "pengetahuan yang teratur untuk produksi", istilah lain menyebutkan teknologi merupakan "pengetahuan tentang bagaimana untuk melakukan sesuatu yang terkait dengan kegiatan ekonomi”, dan teknologi sebagai "pengetahuan tentang bagaimana cara mengendalikan dan mengeksploitasi fenomena ilmiah untuk produksi”.

\section{Produktivitas}

Menurut Syukron (2014:116) dalam pengertian yang lebih luas, produktivitas merupakan hubungan antara output dengan input yang digunakan untuk output tersebut. Atau dengan kata lain produktivitas adalah rasio dari beberapa output tersebut dengan beberapa input.

\section{METODE PENELITIAN}

\section{Populasi}

Populasi dalam hal ini yang dipergunakan adalah semua pekerja di UD. Laut Karya, di Desa Sidohasri, Kecamatan Kenduruan, Kabupaten Tuban yang berjumlah 33 orang. 


\section{Sampel}

Dalam penelitian ini digunakan teknik sampling jenuh karena sampel yang diteliti adalah keseluruhan dari populasi yang ada atau disebut dengan sesus.

\section{Kerangka Konseptual}

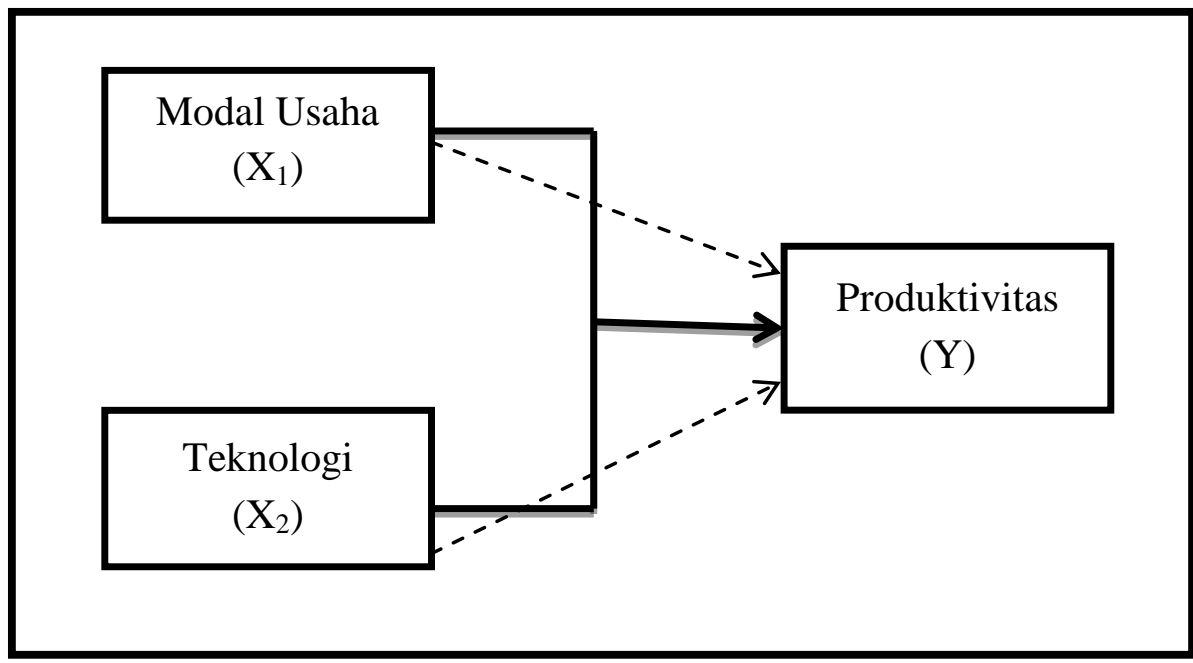

Sumber: Peneliti (2019)

\section{Gambar 1 \\ Kerangka Konseptual}

\section{Hipotesis Penelitian}

Berdasarkan pada Rumusan Masalah yang diajukan, Tujuan Penelitian dan Kajian Teori maka dapat diajukan hipotesis dalam penelitian ini, yaitu :

a. Bahwa variabel Modal Usaha secara parsial berpengaruh signifikan terhadap Produktivitas di Industri pengolahan bahan baku pupuk di UD. Laut Karya.

b. Bahwa variabel Teknologi secara parsial berpengaruh signifikan terhadap Produktivitas di Industri pengolahan bahan baku pupuk di UD. Laut Karya.

c. Bahwa variabel Modal Usaha dan Teknologi secara simultan (bersama-sama) berpengaruh signifikan terhadap Produktivitas di Industri pengolahan bahan baku pupuk di UD. Laut Karya.

\section{Lokasi dan Waktu Penelitian}

Lokasi dari obyek penelitian ini adalah di industri bahan baku pupuk di UD. Laut Karya, di Desa Sidohasri, Kecamatan Kenduruan, Kabupaten Tuban. Waktu penelitian ini dilaksanakan pada tanggal 20 Maret 2019 sampai 20 Juni 2019 untuk melakukan survey lapangan pengumpulan data yang dibutuhkan oleh peneliti.

\section{Jenis dan Sumber Data}

a. Data Primer

Data primer adalah data yang diperoleh secara langsung dari obyek penelitian dengan menggunakan alat pengukur atau alat pengambilan data pengembalikan data Modal Usaha dan Teknologi terhadap produktivitas di 
Industri bahan baku pupuk UD. Laut Karya di Desa Sidohasri, Kecamatan Kenduruan, Kabupaten Tuban.

b. Sumber Data

Sumber data penelitian ini berasal dari responden seluruh pekerja di UD. Laut Karya, di desa Sidohasri, Kecamatan Kenduruan, Kabupaten Tuban, Jawa Timur.

\section{HASIL ANALISIS DAN PEMBAHASAN}

\section{Uji Validitas}

Berdasarkan pada Tabel 1, terlihat nilai setiap indikator pada tabel tersebut memiliki nilai validitas diatas atau lebih besar dari 0,3440 dan signifikan kurang dari 0,05, maka dapat disimpulkan bahwa semua pernyataan untuk variabel Modal Usaha adalah valid dan dapat dilanjutkan ke pengujian selanjutnya.

\section{Uji Reliabilitas}

Berdasarkan Tabel 2, dapat diketahui hasil Cronbach's Alpha pada setiap variabel menunjukkan nilai Cronbach's Alpha lebih dari standar yang disyaratkan yaitu 0,6. Maka variabel Modal Usaha semua pernyataan memiliki tingkat keandalan yang baik dan dapat digunakan dalam analisis penelitian ini.

Tabel 1

Uji Validitas

\begin{tabular}{lccc}
\hline Modal Usaha & & & \\
\hline Indikator & $\mathrm{r}_{\text {hituung }}$ & $\mathrm{r}_{\text {tabel }}$ & $\mathrm{Sig}$ \\
Modal Investasi awal & 0,865 & 0,3440 & 0,000 \\
Modal Kerja & 0,831 & 0,3440 & 0,000 \\
Modal Operasional & 0,865 & 0,3440 & 0,000 \\
Teknologi & & & \\
Teknologi Produksi & 0,911 & 0,3440 & 0,000 \\
Teknologi Tepat guna & 0,884 & 0,3440 & 0,000 \\
Produktivitas & & & \\
Indikator & $\mathrm{r}_{\text {hitung }}$ & $\mathrm{r}_{\text {tabel }}$ & $\mathrm{Sig}$ \\
Efisiensi & 0,784 & 0,3440 & 0,000 \\
Efektivitas & 0,766 & 0,3440 & 0,000 \\
Kualitas & 0,839 & 0,3440 & 0,000 \\
\hline
\end{tabular}

Sumber: Data Diolah, 2019

Tabel 2

Uji Reliabilitas

\begin{tabular}{lc}
\hline Variabel & Cronbach's Alpha \\
\hline Modal Usaha & 0,814 \\
Teknologi & 0,774 \\
Produktivitas & 0,712
\end{tabular}

Sumber: Data Diolah, 2019 


\begin{tabular}{|c|c|c|c|c|c|c|}
\hline \multicolumn{7}{|c|}{$\begin{array}{c}\text { Tabel 3 } \\
\text { Analisis Regresi Linier Berganda } \\
\text { Coefficients }\end{array}$} \\
\hline \multirow[b]{2}{*}{ Model } & & \multicolumn{2}{|c|}{$\begin{array}{l}\text { Unstandardized } \\
\text { Coefficients }\end{array}$} & \multirow{2}{*}{$\begin{array}{c}\text { Standardized } \\
\text { Coefficients } \\
\text { Beta }\end{array}$} & \multirow[b]{2}{*}{$\mathrm{t}$} & \multirow[b]{2}{*}{ Sig. } \\
\hline & & $\mathrm{B}$ & Std. Error & & & \\
\hline \multirow[t]{3}{*}{1} & (Constant) & .951 & .529 & & 1.799 & .082 \\
\hline & Modal.Usaha & .462 & .125 & .499 & 3.680 & .001 \\
\hline & Teknologi & .321 & .116 & .375 & 2.767 & .010 \\
\hline
\end{tabular}

a Dependent Variable: Produktivitas

Sumber: Data Diolah, 2019

Tabel 4

Koefisien Determinasi

Model Summary

\begin{tabular}{llrrr}
\hline Model & R & R Square & Adjusted R Square & Std. Error of the Estimate \\
\hline 1 & .745 & .555 & .525 & .44829 \\
\hline
\end{tabular}

Sumber: Data Diolah, 2019

Analisis Regresi Linier Berganda

Berdasarkan tabel diatas dapat dibuat suatu persamaan regresi untuk variable Modal Usaha (X1) dan Teknologi (X2) terhadap produktivitas (Y) di UD. Laut Karya.

$Y=0,951+0,462 X 1+0,321 X 2$

Dari persamaan regresi linier dapat dikatakan bahwa Modal Usaha (X1) dan Teknologi (X2) berpengaruh terhadap Produktivitas pada UD. Laut Karya.

\section{Koefisien Determinasi}

Pada tabel tersebut diperolah nilai Adjusted R Square yang dihasilkan adalah 0,525. Ini berarti variabel bebas Modal Usaha, Tenaga Kerja, dan Teknologi secara bersama-sama mempengaruhi variabel terikat Produktivitas sebesar 52,5\% dan sisanya 47,5\% (100\%-52,5\%) dipengaruhi variabel lain yang tidak masuk kedalam penelitian ini.

Pada Tabel 4, diperolah nilai Adjusted R Square yang dihasilkan adalah 0,525. Ini berarti variabel bebas Modal Usaha, Tenaga Kerja, dan Teknologi secara bersama-sama mempengaruhi variabel terikat Produktivitas sebesar 52,5\% dan sisanya $47,5 \%(100 \%-52,5 \%)$ dipengaruhi variabel lain yang tidak masuk kedalam penelitian ini. 


\begin{tabular}{|c|c|c|c|c|c|c|}
\hline \multicolumn{7}{|c|}{$\begin{array}{c}\text { Tabel } 5 \\
\text { Uji F (Uji Simultan) } \\
\text { ANOVA }\end{array}$} \\
\hline Model & & $\begin{array}{l}\text { Sum of } \\
\text { Squares }\end{array}$ & Df & $\begin{array}{l}\text { Mean } \\
\text { Square }\end{array}$ & $\mathrm{F}$ & Sig. \\
\hline \multirow[t]{3}{*}{1} & Regression & 7.513 & 2 & 3.757 & 18.693 & .000 \\
\hline & Residual & 6.029 & 30 & .201 & & \\
\hline & Total & 13.542 & 32 & & & \\
\hline
\end{tabular}

a Predictors: (Constant), Teknologi, Modal.Usaha

b Dependent Variable: Produktivitas

Sumber: Data Diolah, 2019

\begin{tabular}{|c|c|c|c|c|c|c|}
\hline & & $\begin{array}{r}\text { Uji } \\
\text { Co }\end{array}$ & $\begin{array}{l}\text { abel 1.6 } \\
\text { Uji Parsial } \\
\text { fficients(a) }\end{array}$ & & & \\
\hline & & $\begin{array}{l}\text { Unst: } \\
\text { Co }\end{array}$ & $\begin{array}{l}\text { Idardized } \\
\text { ficients }\end{array}$ & $\begin{array}{l}\text { Standardized } \\
\text { Coefficients }\end{array}$ & & \\
\hline Model & & B & Std. Error & Beta & $\mathrm{t}$ & Sig. \\
\hline 1 & (Constant) & .951 & .529 & & 1.799 & .082 \\
\hline & Modal.Usaha & .462 & .125 & .499 & 3.680 & .001 \\
\hline & Teknologi & .321 & .116 & .375 & 2.767 & .010 \\
\hline
\end{tabular}

a Dependent Variable: Produktivitas

Sumber: Data Diolah, 2019

\section{Pengujian Hipotesis}

\section{Uji F (Uji Simultan)}

Dari hasil penelitian ini dapat dilihat dari nilai signifikan $\mathrm{F}$ sebesar 0,000. Karena nilai signifikan lebih kecil atau lebih rendah dari 0,05 maka H0 ditolak dan H1 diterima. Ini membuktikan bahwa ada pengaruh secara simultan antara variabel modal usaha dan teknologi terhadap produktivitas.

\section{Uji t (Uji Parsial)}

Dari hasil uji parsial bisa dilihat dari nilai signifikan, diketahui nilai signifikan modal usaha sebesar $0,001<0,05$, hal ini menunjukkan bahwa variabel modal usaha secara parsial berpengaruh signififan terhadap produktivitas.begitu juga dengan nilai signifikan teknologi, memiliki nilai sebesar $0,010<0,05$, berarti variabel teknologi secara parsial berpengaruh signifikan terhadap produktivitas.

\section{SIMPULAN}

Berdasarkan hasil penelitian dan pembahasan yang telah dikemukakan pada bab sebelumnya, maka dapat ditarik kesimpulan sebagai berikut: a) Terdapat pengaruh secara simultan antara variabel Modal Usaha dan Teknologi terhadap Produktivitas. Maka dapat disimpulkan bahwa jika Modal Usaha dan Teknologi ditingkatkan secara bersama-sama maka Produktivitas akan meningkat. b) Diketahui bahwa secara simultan modal usaha berpengaruh signifikan terhadap produktivitas. Maka dapat terlihat bahwa secara parsial modal usaha yang dimiliki 
industri mampu meningkatkan Produktivitasnya. c) Diketahui bahwa secara parsial variabel teknologi dapat berpengaruh signifikan terhadap produktivitas. Maka dapat disimpulkan bahwa semakin baik teknologi yang digunakan dapat meningkatkan produktivitas pada industri tersebut. Berdasarkan hasil penelitian dan kesimpulan yang telah disajikan maka selanjutnya peneliti menyampaikan saran-saran yang kiranya dapat memberikan manfaat pada pihak-pihak yang terkait atas penelitian ini. Adapun saran-saran yang dapat peneliti sampaikan adalah sebagai berikut: a) Modal Usaha merupakan faktor penting dalam membangun sebuah usaha. Dengan adanya modal usaha yang cukup dan dapat mengolah modal usaha itu dengan baik maka dapat meningkatkan Produktivitasnya. Oleh karena itu akan lebih baik apabila UD. Laut Karya dapat memenuhi dan mengatur modal usahanya dengan cukup baik, dan juga, apabila UD. Laut Karya mau dan berani untuk mengambil pinjaman nntuk mengembangkan usahanya agar mampu bersaing dengan industri pengolahan bahan baku pupuk lainnya, maka industri UD. Laut Karya diharapkan dapat meningkatkan kualitas maupun produksi tersebut. b) Teknologi adalah alat yang membantu pekerjaan para pekerja dalam suatu industri. Dengan adanya teknologi maka diharapkan industri dapat menghasilkan produksi sesuai target dan hasil yang diinginkan. Oleh karena itu akan lebih baik apabila industri UD. Laut Karya memiliki teknologi mesin pengering yang lebih memadai agar industri dapat memproduksi lebih banyak barang untuk dihasilkan. c) Bagi peneliti selanjutnya, hendaknya untuk mengembangkan penelitian ini dengan menggunakan variabel atau indikator yang berbeda sehingga dapat diperoleh informasi yang lebih lengkap tentang faktor-faktor yang mempengaruhi peningkatan produktivitas.

\section{DAFTAR PUSTAKA}

Agustina, Tri 2015,Kewirausahaan Teori dan Penerapan Pada Wirausaha dan UKM di Indonesia, Mitra Wacana Media, Bogor.

Arsyad, Lincoln 2016, Ekonomi Pembangunan, Penerbit UPP STIM YKPN, Yogyakarta.

Machmud, Amir 2016, Perekonomian Indonesia Pasca Reformasi, PT. Gelora Aksara Pratama, Jakarta

Syukron A, Kholil M 2014,Pengantar Teknik Industri, Penerbit Graha Ilmu, Yogyakarta. 